Doutora e Mestre em Comunicação e Semiótica pela PUC-SP. Pesquisadora e Professora do Programa de

Pós-Graduação e do Departamento de Design da UNESP, em Bauru. Coordena o Grupo de Pesquisa Design Gráfico Contemporâneo. Responsável pela Editoria do segmento Design da Editora Estação das Letras e Cores. Membro de várias associações, comitês científicos e do corpo editorial de diversas publicações acadêmicas das áreas de Design e de Moda. Presidente da Sociedade Brasileira de Design da Informação - SBDI.

E-mail: monicamoura.design@gmail.com

\title{
Moda sustentável na Bienal Brasileira de Design
}

A III Bienal Brasileira de Design foi apresentada ao público entre os meses de setembro e outubro de 2010. Resultado da iniciativa de importantes realizadores, patrocinadores e apoiadores que assumiram o papel de agentes facilitadores, atuando em conjunto e representando toda a cadeia do design, bem como auxiliando a prestigiar, consolidar e valorizar o design brasileiro'. Viva!

A curadoria geral foi da jornalista, escritora e crítica de design Adélia Borges, que também assinou a curadoria da exposição principal, Design, inovação e sustentabilidade $^{2}$, e da mostra Reinvenção da matéria. 0 evento contou também com outras exposições que tiveram curadorias de personagens significativos do design brasileiro ${ }^{3}$. $E$ ainda abriu espaço para o diálogo com as questões internacionais a respeito do design com o Seminário Internacional Innovation Labse a exposição de design dinamarquês4.

Neste artigo vou me ater a alguns produtos de moda selecionados para a exposição principal, Design, inovação e sustentabilidade. Antes disso, creio que seja importante esclarecer que a exposição trabalhou com temas intrínsecos ao design. A equipe de seleção foi constituída por pesquisadores e profissionais de todas as regiões do país. Além disso, a curadoria também contou com a colaboração dos consultores em sustentabilidade Cyntia Malaguti e Fernando Mascaro. 0 critério principal focou o conceito "do berço ao berço" e levou em consideração três questões essenciais: materiais (matéria-prima, fontes renováveis de recursos, manejo sustentável); processos (técnicas produtivas, redução das sobras, economia de energias naturais, transporte, armazenamento, logística reversa); atitude projetual (tempo de uso do produto, sistemas de uso compartilhado ou temporário, indução a atitudes ecológicas, relação humana, novos padrões de consumo, novos valores de vida).

0 conceito "do berço ao berço", elaborado pelo arquiteto e designer William McDonough e pelo químico alemão Michael Braungart ${ }^{5}$, diz respeito à concepção de um produto e de seus respectivos processos incluindo todos os seus componentes, matéria-prima e materiais que possibilitem a reutilização e o reprocessamento, o que pode gerar um novo produto de qualidade igual ou superior ao produto de origem. Esse processo deve ser desenvolvido de forma efetiva nas questões ecológicas e sustentáveis, ou seja, o sistema utilizado e a cadeia produtiva realizam-se pela relação produção-descarte-produção.

A moda foi muito bem representada por meio de vários aspectos, desde os produtos para o corpo até os produtos para a casa e o bem viver. Tecidos, estamparia, tapeçaria, bijuterias, joias, bolsas e sapatos estiveram presentes destacando o design de moda como um rico segmento em que os aspectos projetuais, de inovação e sustentabilidade estão presentes e movimentam um mercado dinâmico e altamente produtivo.

Tecer, colar, recortar, costurar: tramas no corpo e no ambiente

Os produtos de Renata Meirelles (SP) são resultado de uma concepção plástica e gráfica diferenciada, em constante mutação, que é realizada por meio do emprego da técnica de corte a laser e da costura termoadesiva. Os tecidos são elaborados em diversas possibilidades de composição e associação de camadas, resultando em diferentes texturas e níveis de transparência ou opacidade, além do que, geram movimento graças à leveza do material. Os resultados são destinados a painéis, divisórias, cortinas, xales. Não há sobras nem descartes, uma vez que o negativo dos recortes é utilizado para a confecção de colares, flores, cintos. A designer afirma que integra o artístico e o sustentável, valoriza e desafia os limites da técnica, altera o suporte, trabalha com diferentes dimensões nas 


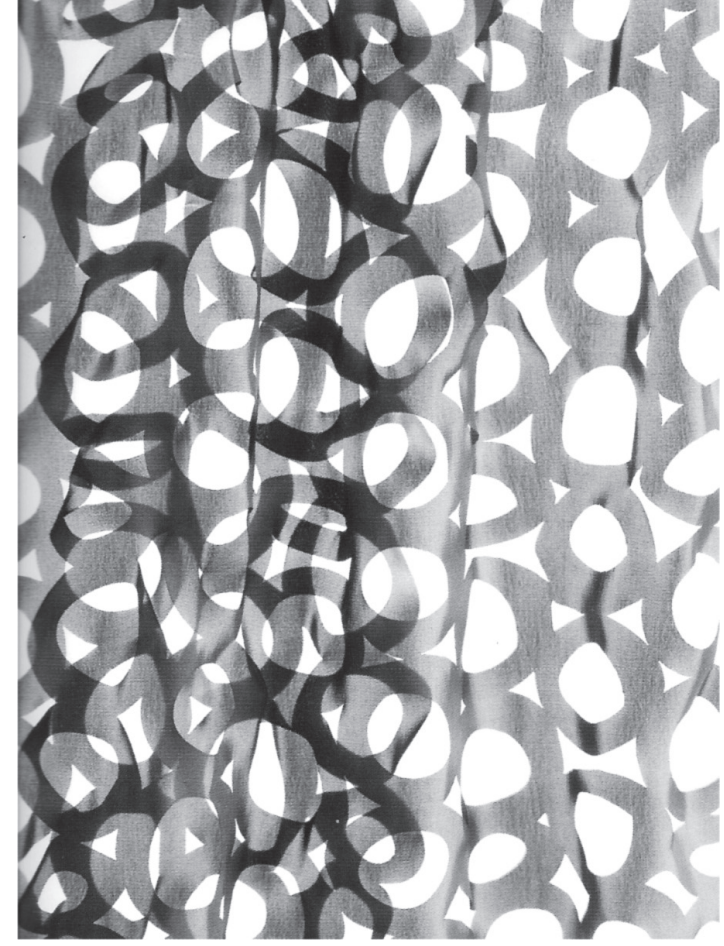

quais os tecidos podem sair do corpo e ir para o espaço, ou vice-versa.

Tecidos sintéticos. Além do corte a laser é utilizada a técnica da costura termoadesiva

Design: Renata Meirelles Produção: Performa Foto: Marie Ange Unbekandt

A Tissume, de Mercedes Montero, de Pirenópolis (GO), resgata a tecelagem artesanal, utiliza fios reciclados PET, algodão orgânico e sobras de tecidos de confecções da região, explorando e criando texturas e dife-

rentes composições cromáticas aplicadas em produtos têxteis e de decoração, enquanto a Trapos e Fiapos, de Teresina (PI), desenvolve redes, colchas, tapetes, mantas, passadeiras, almofadas e tecidos a partir das fibras de taboa e buriti, couro de bode, algodão cru e tinto, tramados em tear manual horizontal e produzidos no sistema de comunidade rural que envolve e gera renda para 30 famílias locais. Por sua vez, Claudia Araujo (SP) desenvolve tapetes produzidos artesanalmente a partir de fio reciclado PET. 0 resultado são padrões diferenciados e exclusivos. As sobras e dejetos são doados ou vendidos para associações locais, fato que estimula o processo contínuo de utilização total da matéria-prima.

Roupas para a casa também merecem a possibilidade da multifuncionalidade nos produtos de Claudia Azeredo, de Pirenópolis (G0). As peças desenvolvidas por essa designer podem "vestir" a parede em forma de painel ou servir como centro de mesa, beirada de poltronas ou sofás, trilhos e caminhos de mesa ou jogos americanos. A rica composição geométrica e com grande exploração cromática remete às referências das colchas de retalho.

\section{Design de superfície em visões diversas}

Anne e Evelise Anicet, do Studio Surface de Porto Alegre (RS), exploram a sobreposição da matéria-prima obtida do descarte das indústrias têxteis e de confecção. Criam tecidos, roupas e acessórios. Utilizam termoadesivo colante, sem poluentes e solventes, misturam fios de diversas naturezas e para 0 e plásticos, gerando novos produtos para a casa

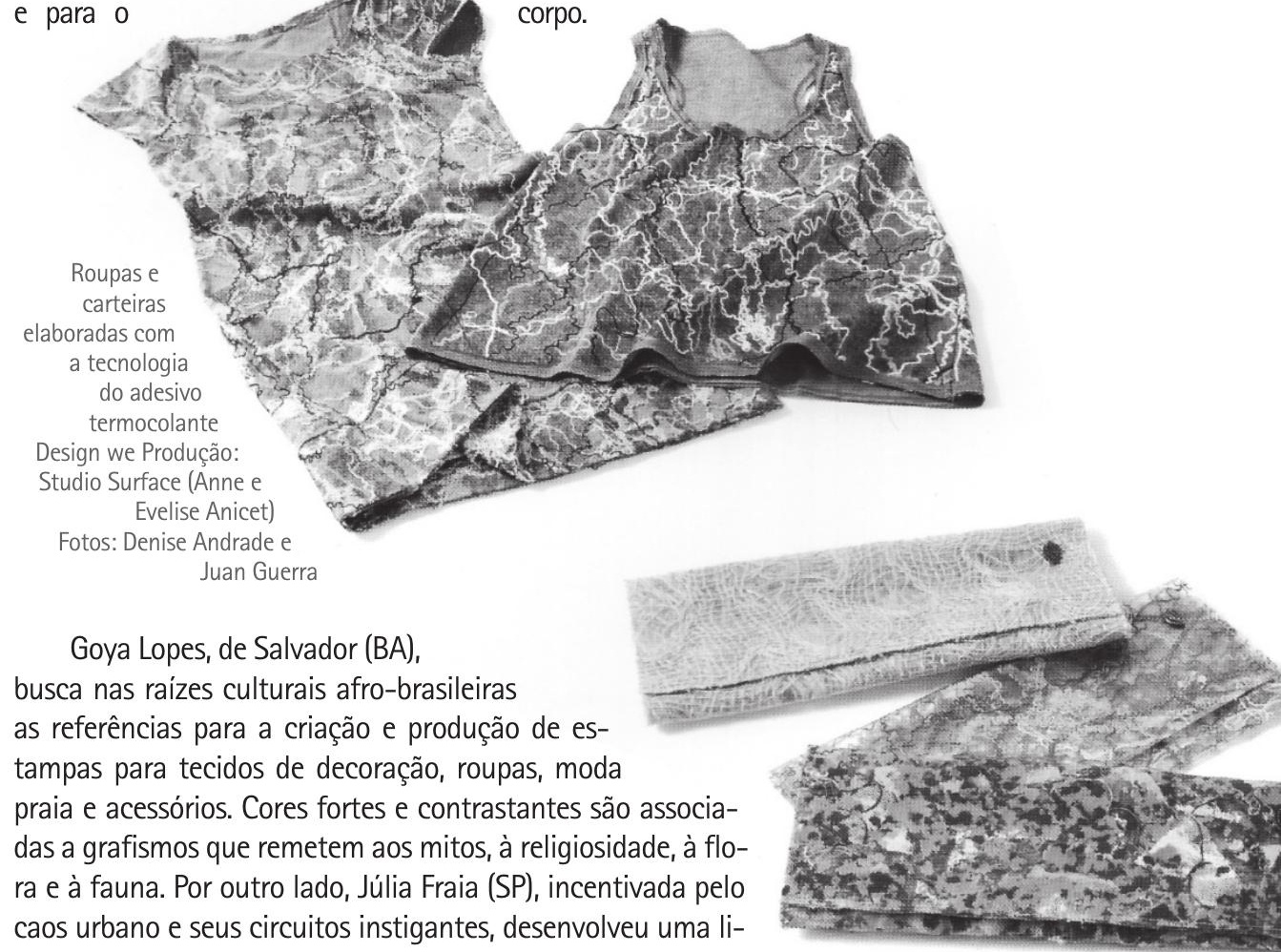


nha de padrões em que as estampas são resultados de imagens e referências da cidade de São Paulo, impressos digitalmente com pigmentos à base de água e tecidos 100\% algodão. Os detalhes geométricos, arquitetônicos, o emaranhado dos fios elétricos e os postes de iluminação constituem os tecidos, almofadas, jogos de cama e bolsas.

Tecidos | Design: Goya Lopes Produção: Didara

Enquanto isso, em Caxambu, sul de Minas Gerais, Carlos Simas associa a fotografia e a captação de imagens observando horizontes não convencionais. Fotografa a flora e os detalhes das copas de árvores a partir de seu observatório particular, uma plataforma de arvorismo criada por ele e sua equipe, de onde tem ângulos de visão privilegiada. Isso tudo a partir de sua "Fazenda de Imagens" que denomina Reserva Particular do

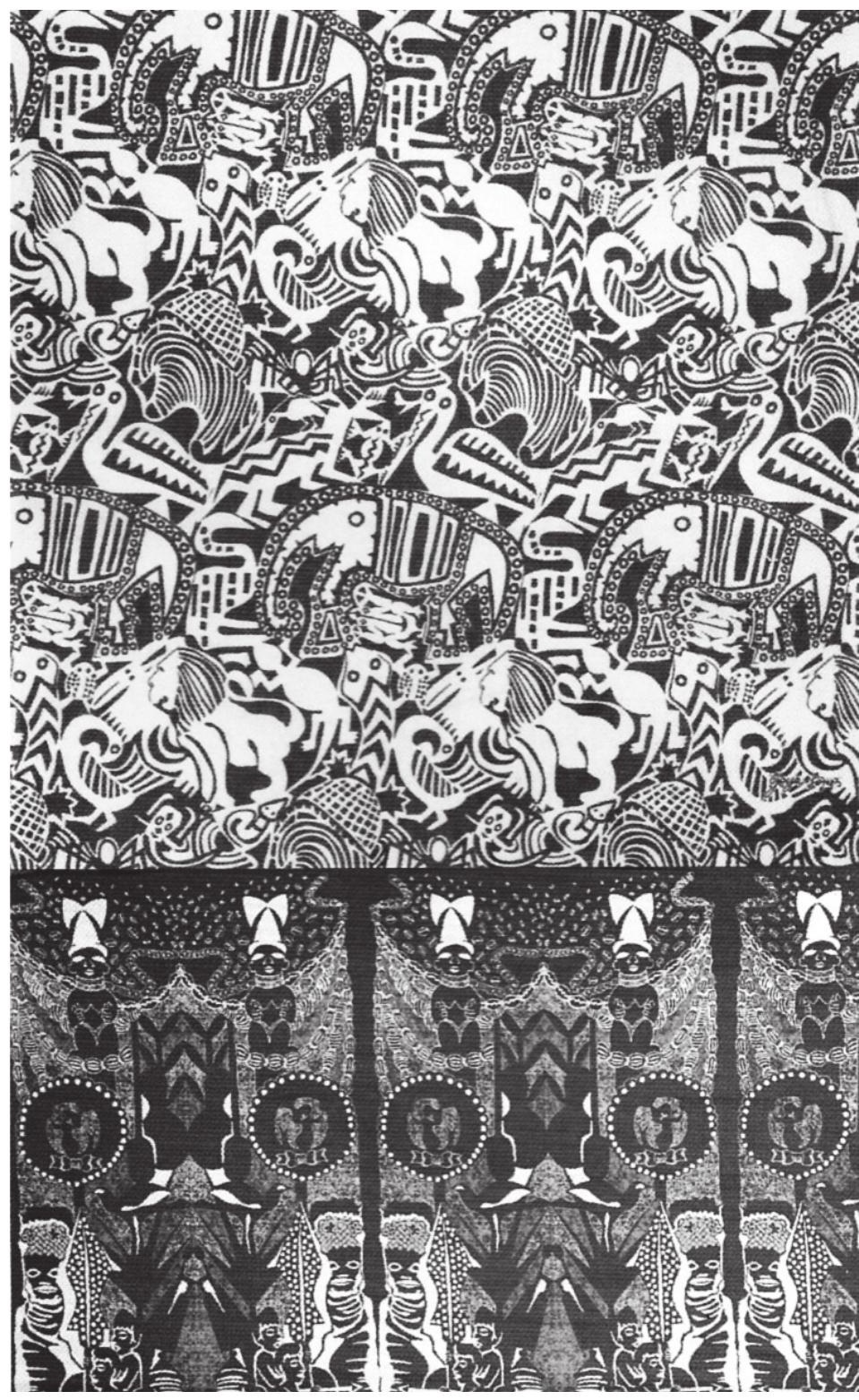

Patrimônio Natural (RPPN), local onde nada é retirado da natureza circundante. As imagens fotografadas são retrabalhadas e convertidas em padrões de estampas para impressão digital sobre tecidos. Com isso atende a vários clientes e marcas, como a linha de moda praia da Blue Man, que utilizou essas padronagens em biquínis, maiôs, bermudas e outras peças.

Bermuda | Design: Fazenda de Imagens e Eco-Lógica Artes, Carlos Simas Produção: Azulay e Cia (Blue Man)
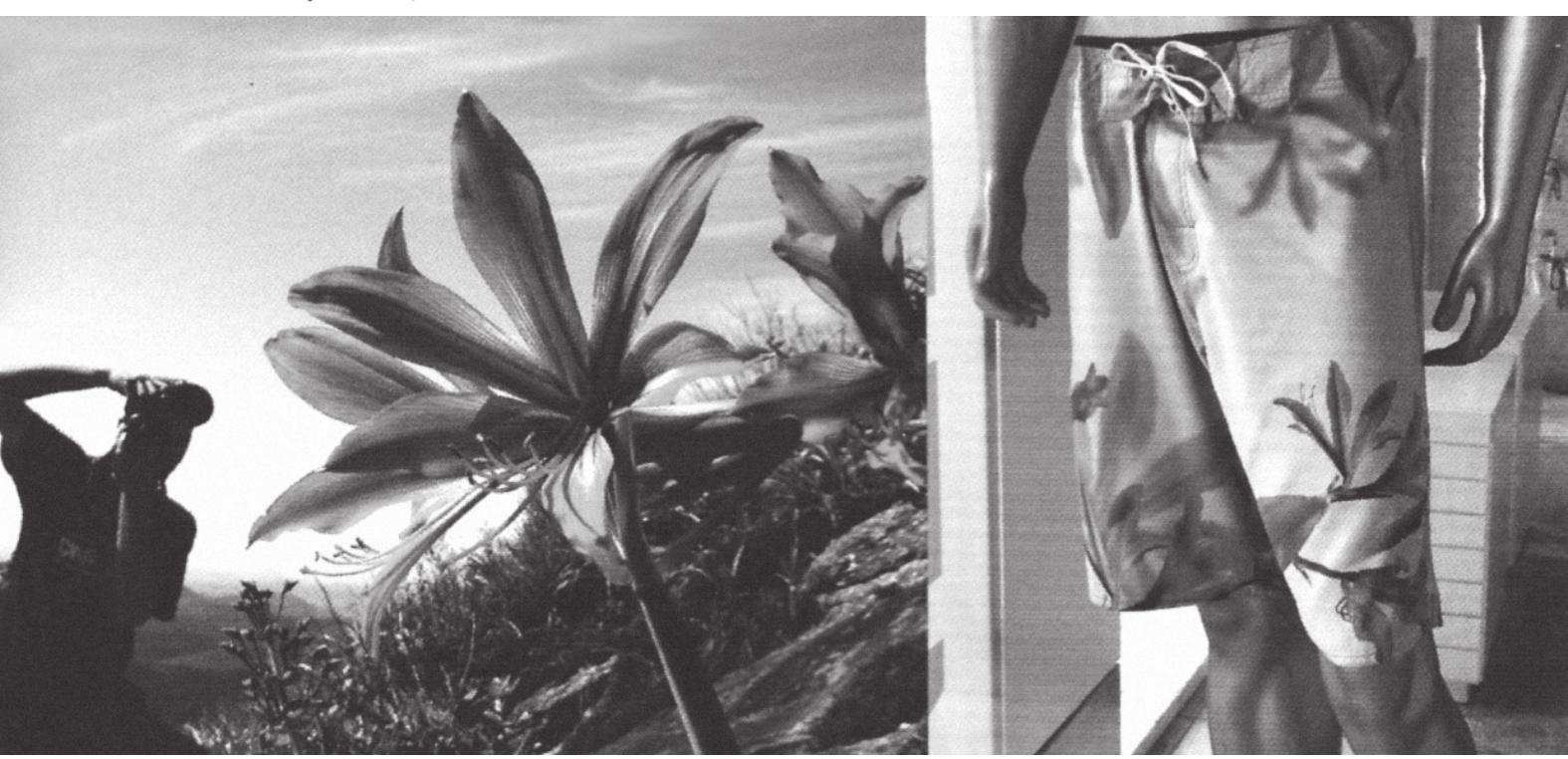
Acessórios multifuncionais: bijuterias que vêm do lixo e joias de vestir

Tiana Santos, de Recife (PE), trabalha com os PETs, recolhidos pelos catadores de Recife, que são transformados em colares e recebem em seu interior materiais variados, como bolinhas de plástico ou tecido. 0 processo de produção envolve artesãos, designers e artistas que ajudam na diminuição do lixo urbano. Angela Carvalho e Monica Carvalho (RJ) produzem bijuterias e produtos para casa a partir dos descartes dos salões de beleza cariocas. Embalagens de cosméticos e de diferentes tipos de produtos utilizados nos salões, geralmente de plástico, são fontes ricas de materiais para o desenvolvimento das peças da coleção denominada Design sustentável. Além do aspecto de reaproveitamento e consequente diminuição do lixo da cidade, há o desenvolvimento do associativismo, a geração de renda para comunidades populares e o incentivo para atitudes de preservação ambiental. Mana Bernardes (RJ) também utiliza PET e outros materiais descartados do cotidiano e os transforma em bijuterias e acessórios com produção artesanal, como a coleção de sua criação selecionada para a Bienal, nomeada Índios urbanos.

Pulseira da Coleção Índios Urbanos

Design e Produção: Mana Bernardes

Já Claudia Villela Salles, de Brasília, associa a produção artesanal a materiais industriais, tais como o couro, a resina, o polietileno e a madeira. A série intitulada Jóias brincantes é constituída por objetos que transitam entre a joia e a bijuteria; são peças articuláveis que oferecem várias possibilidades de uso, tais como um colar que pode ser também uma pulseira, um cinto, um broche ou um anel. Essa ação ativa do usuário que configura a peça conforme sua disposição, atribuindo usos diferenciados e atuando de forma criativa ao compor seu look, é também proposta norteadora da série denominada Jóias retenso de Joana Prudente, de Brasília. Essa designer utiliza cobre proveniente de restos de fiação elétrica e prata reciclada do nitrato de materiais fotográficos - a prata em fitas temperadas, que confere à peça maior flexibilidade, resulta em economia de material, maior praticidade e conforto, além de possibilitar a ação ativa do usuário na composição e configuração da peça em razão de seu formato de mola. A mesma peça pode ser utilizada como colar, em diferentes combinações, pulseira ou cinto e pode ser vestida da forma como se desejar.

\section{Calçados para brincar e calçados inspirados na cultura popular}

A linha de sapatos infantis da designer Priscila Callegari, da Ciao Mao (SP), tem o sistema de acessórios intercambiáveis constituídos por cadarços e sianinhas elásticas com estampas variadas. A estrutura do calçado apresenta o cabedal em tecido e/ou couro, sola de borracha reciclada e palmilha em látex expandido. A criança determina e finaliza o produto conforme sua opção de composição. Ainda em relação aos calçados, a designer Fabíola Bergamo (SP), atuando em conjunto com a Dai Artefatos de Junco, desenvolveu uma linha de peças e sandálias, o que possibilitou a ampliação de mercado e supriu a capacidade produtiva dos pequenos produtores do Vale do Ribeira. Por sua vez, 
Jailson Marcos, de Recife (PE), traduziu a sandália masculina sertaneja para o homem urbano. Com produção semiartesanal, utiliza couro de bode e de boi, palha, tecidos e alguns elementos sintéticos. Atende a várias marcas de moda. Nessa linha de resgate popular, a Alpargatas (SP) traz de volta as alpercatas renovadas pelo solado de borracha e lona colorida. A linha também é constituída pelos tênis de cano baixo e médio.
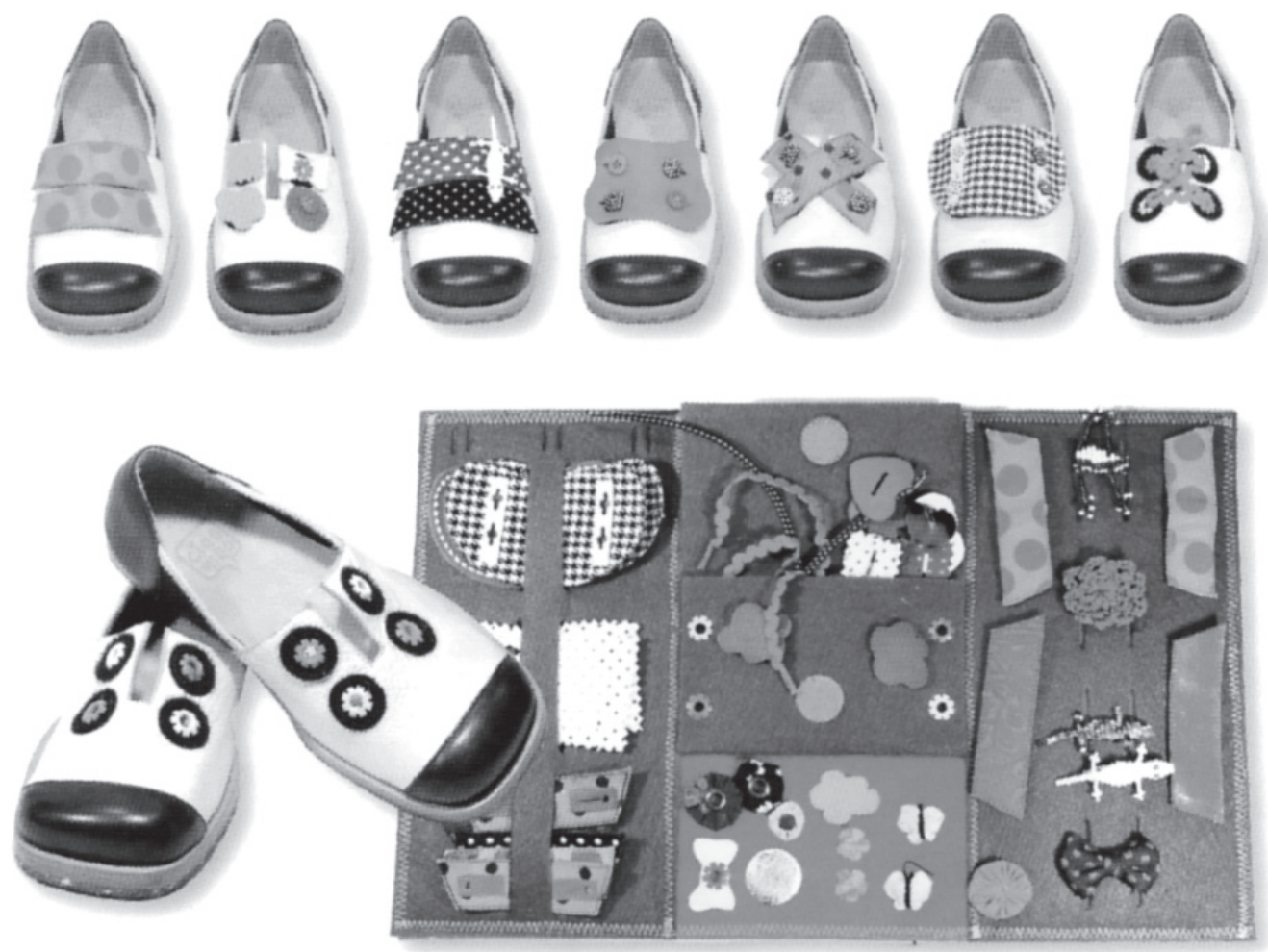

Calçados Infantis Ciao Miao Design: Priscila Callegari | Produção: Ciao Mao | Fotos: Priscila Callegari

Ecobags que reciclam tradições, comunidades e materiais

Prazeres Accioly, de Recife (PE), concebe e produz uma linha de acessórios para o corpo e para a casa pela marca Arte Primitiva. Materiais como a palha da seda, extraída do casulo do bicho-da-seda e geralmente descartada pela indústria, e a pele de pescada, o couro vegetal e o algodão são aproveitados. A produção é artesanal a partir da tessitura em tear manual e do tingimento de fios. Não há descarte de matérias-primas, uma vez que são reaproveitadas na produção das peças ou doadas a comunidades para o desenvolvimento de outros trabalhos.

A concepção do oestudio (RJ) e a produção da Amazonlife resultaram em uma linha de bolsas e tênis obtidos pelo emprego do couro vegetal (laminado natural de borracha), algodão orgânico, linha, juta, palha e sementes. 0 couro vegetal provém do extrativismo sustentável da Amazônia, fato que possibilita a geração de renda para a manutenção da floresta e das populações locais. Também não há descarte de material, uma vez que todas as sobras são reaproveitadas e reutilizadas.

A ecobag de Sofia Nanka (SP) relaciona as questões culturais e valoriza a tradição e a memória da cultura japonesa ao retomar a embalagem de presente denominada furoshiki em uma versão contemporânea e com o objetivo de substituir as sacolas plásticas. A bolsa pode assumir diferentes configurações e propostas a partir de um quadrado de tecido. 0 Studio Lúmem, de Curitiba (PR), desenvolveu o ecobag-car, um objeto que faz as funções de carrinho no supermercado, de caixa de transporte no trajeto mercado-carro-casa e pode ser deixado no carro para evitar o esquecimento das ecobags. 0 ecobag-car é desenvolvido em alumínio, portanto é leve (pesa $2 \mathrm{~kg}$ ), utiliza lona de banners descartados e tecido obtido pela reciclagem de PET. 


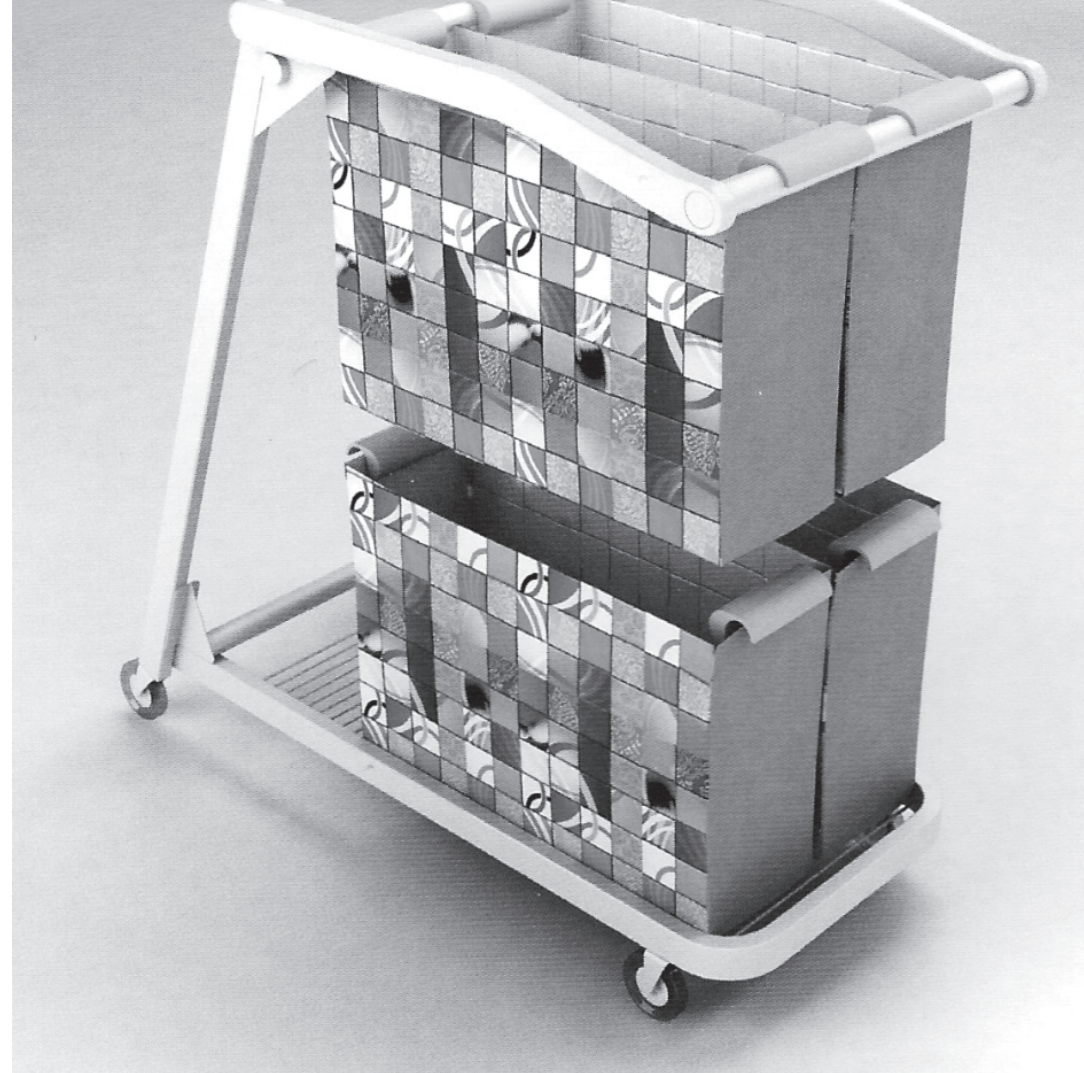

Ecobag-car | Design: Studio Lúmen (Karine Mitsue Kawamura, Silvio Silva Junior e Guido Lautert Dezordi) Produção: In Vitro ${ }^{6}$

Pudemos ver nesses exemplos, eleitos entre outros presentes na edição da Bienal de Design 2010, a importância do design de moda em sua relação com a inovação, a originalidade e a sustentabilidade, contribuindo de forma significativa para um mundo que respeita o ser humano, o ambiente e a sociedade, explorando a criatividade, as diversas possibilidades de uso, de produção e gerando alternativas de desenvolvimento.

\section{NOTAS}

${ }^{[1]}$ Ministério da Cultura, Movimento Brasil Competitivo, Programa Brasileiro do Design, Ministério do Desenvolvimento, Indústria e Comércio Exterior. A Bienal Brasileira de Design 2010 ocorreu na cidade de Curitiba e foi realizada pelo Centro de Design do Paraná e pela Federacão das Indústrias do Estado do Paraná e o seu Centro Internacional de Inovação, articulador de serviços do Sesi, Senai, IEL e de entidades nacionais e internacionais que operam em rede e oferecem formação para a gestão de empresas inovadoras por meio da Universidade e da Indústria - Unindus. A correalização foi da prefeitura de Curitiba e da Universidade Positivo. Teve como patrocinadores as empresas Fiat, Santander, Natura e Electrolux e como copatrocinadores as instituições Sebrae, Agência Brasileira de Desenvolvimento Industrial - ABDI, BNDES, Ministério da Ciência e Tecnologia, além de várias parcerias e apoios de associações e revistas da área. Vemos aí a união dos setores político-governamentais, industriais, empresas públicas e privadas, órgãos representativos dos profissionais da área, do setor de educação e ensino e a mídia especializada.

${ }^{[2]}$ A exposição Design, inovação e sustentabilidade foi realizada no espaço de exposições da Fiep/Cietep. A exposição Reinvenção da matéria foi levada a público no Museu Oscar Niemeyer.

${ }^{[3]}$ As curadorias em dupla realizadas por André Stolarski e Rico Lins para a mostra de cartazes inéditos Sustentabilidade: e eu com isso?; Freddy Van Camp e Ivens Fontoura para a mostra histórica Bienais de design: primórdios de uma idéia: Antonio Razera Neto e Renato Brandão na mostra do projeto Memória do design no Paraná. As curadorias individuais foram desenvolvidas por Jaime Lerner para a mostra Design urbano: uma trajetória; Angélica Santi para a mostra de resgate histórico do design brasileiro Memória da indústria: o caso da Cimo; Ivens Fontoura para a mostra de produtos resultantes de projetos de estudantes de todo o país, denominada Novissimos.

${ }^{[4]}$ Realizada sob a curadoria do trio Tina Midtgaard do Danish Design Centre, Karen Kjaergaard do Danish Crafts, Kjersti Wikstrom do Danish Architecture Centre. A mostra denominada It's a Small World demonstrou como os designers dinamarqueses estão discutindo e trabalhando com temas contemporâneos, tais como a sustentabilidade, as novas tecnologias e o consumo. Vale lembrar que todas as exposiç̃es, as palestras e todos os painéis estão disponíveis em vídeos no site <www. bienalbrasileiradedesign.com.br/bienal2010> que conta com ações interativas mesmo após o término do evento - uma forma excelente de possibilitar o acesso a todos os interessados no assunto e de disseminar informações a respeito do design brasileiro.

${ }^{[5]}$ McDonough, William; Braungart, Michael. Cradle to cradle. Nova York: North Point Press, 2002.

${ }^{[6]}$ Fonte das imagens: III Bienal Brasileira de Design. Curadoria geral Adélia Borges. Curitiba: Centro de Design Paraná, 2010, p. 58, 59, 110, 121, 150, 168 e 175, respectivamente.

\section{SAIBA MAIS}

Bienal Brasileira de Design 2010 Curitiba. Curitiba: Centro de Design Paraná, 2010. Acesse: $<$ www.bienalbrasileiradedesign.com.br>. 